\title{
A Note on Language
}

FIELDWORK FOR THIS STUDY was conducted in Hebrew, Arabic, and English. Hebrew or Arabic terminology is generally transcribed using characters easily understandable to English readers, rather than using extensive diacritics. The letters ayin, chet, and qaf, for example, are approximated to the English characters ' $a$, $k h$, and $q$, respectively. When referring to Bedouin colloquial Arabic terms, I transliterate the colloquial, rather than the Modern Standard Arabic pronunciation. Unless otherwise noted, all translations in the text are my own.

Choosing conventions for labeling people and places in a context of sociopolitical conflict is notoriously sensitive. An array of labels exists to identify approximately the same group of people: "Bedouins," "Bedouin Arabs," "Israel's Arab citizens," and "Bedouin Palestinians," to name a few. Group belonging and the proper terms for demarcating insiders from outsiders are key elements of contestation in the conflicts I study. Do Negev Arab residents have more meaningful connections with Jewish Israelis or with Palestinians of the West Bank and Gaza? Are Bedouins a distinct cultural group, or is this label an artifact the Israeli government uses to weaken Arab unity? Because these are not idle academic questions of definition, I choose my terminology carefully. "Bedouin Arab" encompasses the multiple senses of belonging most commonly expressed by the Negev residents with whom I spoke, so I prefer this term. However, when referring to others' perspectives in the text, I use their terminology. The label "Jewish Israelis" distinguishes other residents of my research site from the global ethnoreligious group of "Jews." Though this label is less contested, there are those who find it restrictive, for instance those selfidentifying as "Arab Jews," who call for recognition of a common Arab identity that is not negated by Jewishness. Social identity labels are ethnographically 
useful because they convey common understandings about group boundaries in Israel. Unfortunately, the labeling also risks reifying these group boundaries and sidelining alternative notions of identity and relatedness.

Place naming is also fraught with historical and contemporary power relations. When discussing a place within the narrative of a particular group, I use the name commonly attributed by that group, such as "Naqab" among Arabic speakers and "Negev" among Hebrew speakers. Otherwise, I use common English names (in this case, "Negev"), where these are available.

To guard my research participants' anonymity, personal names in the text are pseudonyms, as are names of the two small communities that feature prominently in this book: 'Ayn al-'Azm for the Bedouin township and Dganim for the Jewish moshav. Community pseudonyms are not always sufficient to protect residents from unwanted scrutiny, though (Scheper-Hughes 2000). Thus, while I include enough detail about these places and their residents to accurately explore the socioenvironmental dynamics shaping land relations and views of land conflict, I sometimes alter identifying information to safeguard the privacy of those who taught and talked with me. Two exceptions to the use of pseudonyms include public figures (for example, governmental officials and NGO representatives) and the names of Bedouin unrecognized villages. Bustan's leaders requested that the organization's real name be used. When referring to members' activities in public contexts, I use real names, while for private conversations I use pseudonyms. When writing of unrecognized villages that are pursuing recognition from the Israeli government and public, I do not wish to repeat the social erasure against which they struggle.

Finally, the text distinguishes between verbatim and reconstructed statements. Any text set in quotation marks represents a verbatim transcript of a statement. When reported speech is based on field notes rather than a full transcript, it is not placed in quotation marks. 